\title{
METODE
}

\section{FOTOGRAMETRIČNI IN LIDARSKI OBLAKI TOČK}

\author{
AVTORICA \\ dr. Mihaela Triglav Čekada \\ Geodetski inštitut Slovenije, Jamova 2, SI - 1000 Ljubljana, Slovenija \\ mihaela.triglav@gis.si
}

DOI: $10.3986 / G V 89106$

UDK: 528.711

COBISS: 1.02

\section{IZVLEČEK}

\section{Fotogrametrični in lidarski oblaki točk}

$V$ prispevku so opisane štiri metode izdelave oblakov točk: (a) aerolasersko in (b) terestrično lasersko skeniranje, (c) aerofotogrametrični postopek uporabe fotografij velikega formata ter (d) terestrični fotogrametrični postopek oziroma bližnjeslikovna fotogrametrija, kjer lahko objekt fotografiramo iz roke ali iz letalnika. Opisane so prednosti in slabosti posamezne metode. Pred uporabo različnih oblakov točk za izračun višinskih ali prostorninskih sprememb, moramo preučiti gostoto točk $v$ posameznem oblaku točk ter višinsko in položajno ujemanje med oblakoma točk. Navedeni so nasveti, kako pri navedenih postopkih dosežemo najboljši rezultat.

\section{KLJUČNE BESEDE}

oblak točk, lasersko skeniranje, fotogrametrija, slikovno ujemanje, grajenje strukture iz gibanja

\section{ABSTRACT \\ Photogrammetric and lidar point clouds}

The paper describes four methods for point cloud generation: (a) aerial and (b) terrestrial laser scanning, (c) an aerophotogrammetric process where large-format aerial photographs are used, and (d) a terrestrial or close-range photogrammetric process where an object can be photographed from a hand or from a drone (unmanned aerial vehicle). We describe the advantages and disadvantages of each method. If we use two point clouds to calculate heights or volume changes, we should evaluate the density of each point cloud and their vertical and horizontal discrepancies. The guidelines are given how to achieve the best results using mentioned methods.

\section{KEY WORDS}

point cloud, lidar, photogrammetry, image-matching, structure-from-motion

Uredništvo je prispevek prejelo 10. oktobra 2016. 


\section{Uvod}

Oblak točk je oblika zapisa podatkov o nekem objektu v obliki zelo gostih točk, ki niso med seboj povezane ter, kjer ima vsaka točka svoje koordinate in je lahko opremljena še z drugimi podatki. Ti drugi podatki so na primer barva točke (pri fotogrametričnih postopkih), intenziteta odboja, red odboja (pri laserskih postopkih). Opis nekega objekta v obliki oblaka točk se je pojavil z uvedbo laserskega skeniranja kot metode izmere. Vendar oblaki točk niso omejeni zgolj na lasersko skeniranje, saj jih lahko izdelamo tudi $\mathrm{z}$ drugimi metodami. $Z$ vse večjo razširjenostjo brezpilotnih letalnikov prihajajo v ospredje tudi fotogrametrične metode za izdelavo oblakov točk. Na letalnikih so zaradi večje cenovne sprejemljivosti večinoma nameščeni fotoaparati in ne laserski skenerji. Prav tako izdelavo oblaka točk omogočajo tudi fotografije, narejene iz roke $\mathrm{z}$ različnimi nemerskimi fotoaparati - od klasičnih fotoaparatov do mobilnih telefonov. Postopek izdelave oblakov točk zato ločimo na laserske in fotogrametrične.

Zadnje desetletje se vse bolj uveljavlja obravnava oblaka točk kot končnega izdelka tudi v bližnjeslikovni fotogrametriji. Pred tem se ga je obravnavalo kot neobvezno vmesno fazo pri izdelavi geometrijsko urejenih digitalnih modelov višin ali topološko urejenih žičnih modelov. Kljub nekaterim predvidevanjem, da bo lasersko skeniranje popolnoma izpodrinilo različne fotogrametrične postopke, se v zadnjih letih dogaja ravno nasprotno; fotogrametrično izdelani oblaki točk pridobivajo na veljavi, saj omogočajo izdelavo oblakov točk $\mathrm{z}$ vse večjo gostoto in $\mathrm{v}$ nekaterih primerih celo prekašajo izdelke laserskega skeniranja (Leberl in sodelavci 2010; Gruen 2012). To so omogočili novi algoritmi in izboljšave računalniške strojne opreme (na primer izvajanje izračunov na grafični kartici), ki omogoča veliko hitrejše računanje (Remondino in sodelavci 2014).

Iz oblakov točk s pomočjo različnih interpolacijskih metod izdelamo digitalne modele višin (različne digitalne modele površja kot tudi digitalne modele reliefa). Le-ti nam omogočajo raznovrstne analize prostorninskih sprememb od izračuna prostornin aktivnih zemeljskih plazov do prirastka rastja. Fotografije in oblake točk lahko uporabimo tudi za izdelavo ortofoto posnetkov. Nenazadnje iz oblakov točk lahko izdelamo topološko urejene žične modele za 3R-tisk ali izdelamo načrte različnih meril.

Vendar, ko govorimo o različnih oblakih točk, ne moremo posplošiti, da imajo vsi enovito gostoto točk, ker je ta zelo odvisna od metode, s katero smo jih izdelali. Zato bomo v tem članku predstavili nekatere metode izdelave oblakov točk, lastnosti oblakov točk in kaj te lastnosti pomenijo za njihovo nadaljnjo uporabo. Zagovarjali bomo tudi nujnost primerjave gostot različnih uporabljenih oblakov točk in primerjave točnosti georeferenciranja (poravnava oblakov točk v prostoru) pred uporabo oblakov točk za doseganje najboljših rezultatov.

\section{Izdelava oblaka točk}

Oblak točk ima ločeno zapisane koordinate vsake 3R-točke v prostoru, vendar te točke po prostoru večinoma niso enakomerno razporejene. Posamezne točke imajo lahko poleg koordinat kot atributno vrednost zapisano še vrednost intenzitete odboja (laser) ali barvno vrednost slikovnega elementa. Na laserske točke pripišemo barvno vrednost iz ortofota, ki ni bil nujno posnet $\mathrm{v}$ času laserskega skeniranja, torej je lahko tudi starejši ali novejši kot oblak točk (slika 1). V fotogrametričnih postopkih izdelave obarvamo točke neposredno $\mathrm{v}$ fotogrametričnem postopku izdelave oblaka točk iz posnetkov ali, enako kot pri barvanju laserskih točk, naknadno s pomočjo podloženega ortofota. Pri laserskem skeniranju imajo lahko točke dodane tudi druge atribute, kot sta na primer red odboja (prvi odboj od mnogih, zadnji odboj od mnogih) in razred klasifikacije (tla, različno visoko rastje, stavbe). Zato so oblaki točk zapisani v vektorskem zapisu kot niz koordinat $\mathrm{z}$ dodanimi atributnimi vrednostmi. Pri laserskem skeniranju se je uveljavil zapis oblakov točk v formatu LAS. V fotogrametričnih postopkih pa so oblaki točk shranjeni v zapisih, ki so odvisni od posameznega računalniškega programa, v katerem je bil tak oblak točk izdelan (na primer format PST), vendar jih je večinoma mogoče izvoziti v zapis LAS. 

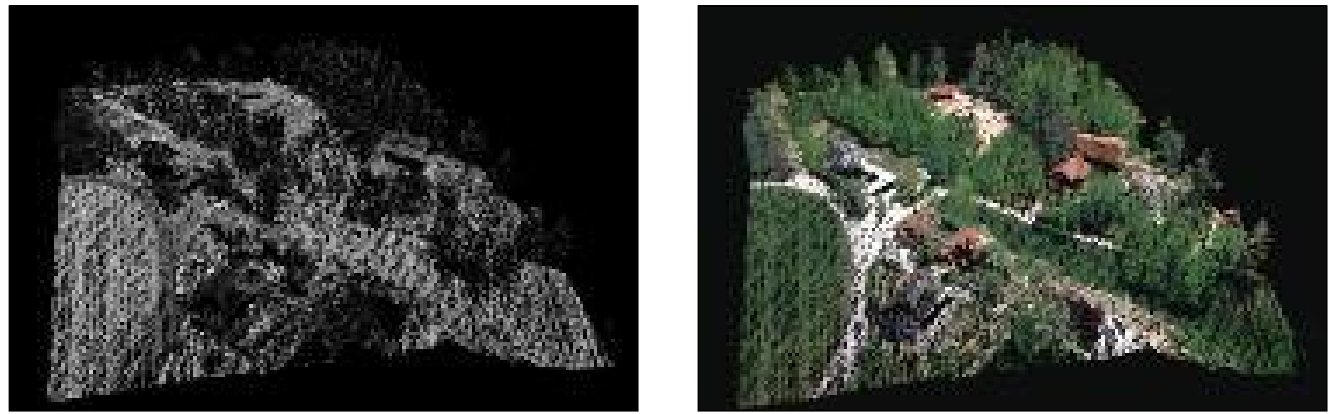

Slika 1: Aerolaserski oblak točk v 3R-pogledu, kjer so iste točke pobarvane po intenziteti odboja (levo) in barvni vrednosti podloženega ortofota (desno).

Oblak točk lahko pridobimo na dva načina:

- $\mathrm{z}$ neposredno izmero $\mathrm{z}$ aero- ali terestričnim laserskim skeniranjem,

- $\mathrm{z}$ izračunom s samodejnimi fotogrametrični postopki obdelave velikega števila fotografij oziroma aerofotografij z velikimi preklopi (vsebina na dveh fotografijah s preklopom je na območju preklopa enaka, le kot pod katerim je bila posamezna fotografija posneta, je drugačen).

Neposredna izmera $\mathrm{z}$ aerolaserskim ali terestričnim laserskim skeniranjem omogoča izdelavo oblakov točk, katerih bistvena lastnost je, da se laserski žarek na svoji poti čez rastje odbije od več predmetov. Tako dobimo točke različnega reda odboja: prvi odboj od več, drugi odboj od več ali zadnji odboj od več (slika 2). Zato dobimo na območju pokritem z rastjem večjo skupno gostoto točk kot na pozidanih območjih ali območjih brez rastja, kjer se posamezen žarek odbije samo od enega predmeta. Zaradi te lastnosti oblak točk narejen $\mathrm{z}$ aerolaserskim skeniranjem, omogoča preučevanje vertikalne strukture gozda ali drugega rastja.

V kolikor želimo oblak točk uporabiti za izdelavo digitalnega modela višin, kjer je zapisana za vsako položajno točko samo ena višina, moramo točke v njem pred tem klasificirati, tako da nam ostanejo le tiste točke, ki označujejo ploskev, ki jo želimo prikazati v našem digitalnem modelu višin. S klasifikacijo pridobimo različne razrede laserskih točk, ki jih po potrebi odstranjujemo ali dodajamo. Če želimo

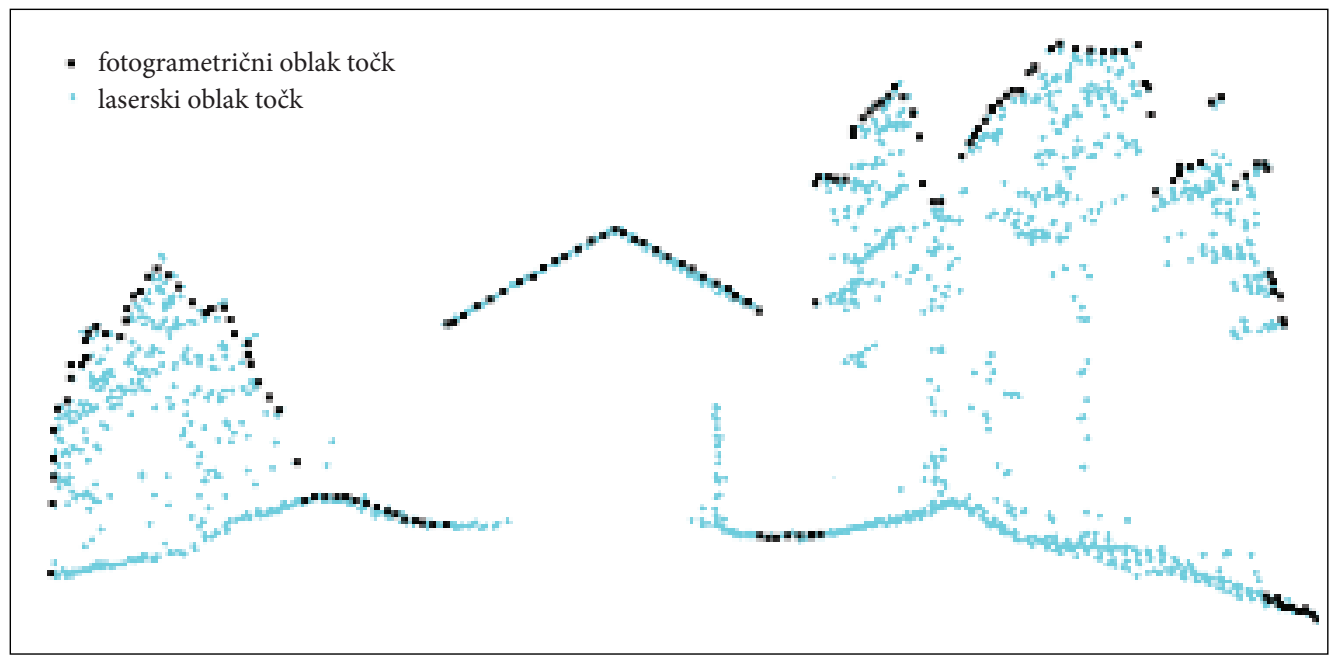

Slika 2: Točke v laserskem (modre) in fotogrametričnem oblaku točk (črne). 
izdelati digitalni model reliefa, ohranimo samo točke tal (razred tla). V kolikor pa želimo izdelati digitalni model krošenj, ohranimo samo prve odboje po vrhovih krošenj (uporabimo razred visoko rastje).

Druga pomembna lastnost laserskega skeniranja je, da imajo točke v oblaku točk enovito točnost, ki je najbolj odvisna od oddaljenosti od objekta snemanja in kota skeniranja (Triglav Čekada, Crosilla in Kosmatin Fras 2009). Točke laserskega oblaka točk posameznega snemalnega pasu dobimo z direktnim georeferenciranjem, kjer prek znanih povezav med senzorji na nosilcu snemanja (laser, globalni navigacijski satelitski sistem (GNSS), inercialna navigacijska enota (INS)) in samo lokacijo nosilca snemanja izračunamo koordinate točk v prostoru. Da odstranimo manjša neujemanja med snemalnimi pasovi, le-te naknadno še poravnamo, največkrat s pomočjo ujemanja na ravnih ploskvah, kot so strehe stavb (slika 3a).

Oblake točk izračunamo s samodejnimi fotogrametričnimi postopki obdelave večjega števila fotografij, kar bomo opisali v nadaljevanju. Ker pa oblak točk dobimo iz fotografij, kjer je prikazan samo vrhnji sloj rastja (slika 2), dobimo v nasprotju od lasersko izdelanih oblakov točk tudi pri rastju zgolj eno višino rastja, praviloma vrhnjo točko. Strukture pod vrhnjo točko (na primer tla) praviloma ne moremo dobiti iz fotogrametrično izdelanih oblakov točk. Deloma lahko dobimo tla pod rastjem le v primeru zelo redkega rastja.

Postopki samodejne obdelave velikega števila fotografij so večinoma opisani kot uporaba algoritmov zelo gostega slikovnega ujemanja (angleško very dense image matching) (slika 3b) ali algoritmov za sočasno določitev notranjih ter zunanjih parametrov orientacije in hkratni izračun 3R-oblaka točk postopek imenovan "grajenje strukture iz gibanja» (Structure-from-Motion - SfM) (slika 3d). Slikovno ujemanje so razvili fotogrametri, vzporedno pa so strokovnjaki s področja računalniškega vida (computer vision) razvili algoritme za sočasno določitev parametrov notranje in zunanje orientacije ter hkratni izračun 3R-oblaka točk. Zaradi različnih strokovnih področij, v katerih sta se metodi razvili, v člankih najdemo za opis istih parametrov različno terminologijo, vendar pa algoritma dajeta enak končni rezultat, to je oblak točk (Remondino in sodelavci 2014; Kosmatin Fras in sodelavci 2015).

Na sliki 3 so štirje najpogosteje uporabljeni postopki za izdelavo oblakov točk. Razdeljeni so na postopke, kjer je nosilec snemanja v zraku (aeropostopki) (sliki 3a in 3b) in na terestrične postopke, kjer je nosilec snemanja na tleh ali zelo nizko nad tlemi (sliki 3c in 3d). Med slednje smo uvrstili tudi snemanja z brezpilotnimi letalniki. Pri aeropostopkih, kot sta aerolasersko skeniranje ali aerofotografiranje, smo za dosego dobre točnosti močno odvisni od GNSS-meritev in INS-meritev na nosilcu snemanja, $\mathrm{s}$ katerimi meritve umestimo v prostor (direktno georeferenciranje podatkov) že v samem postopku izdelave oblaka točk. Tudi mobilne snemalne sisteme (mobile mapping system), ki za umestitev v prostor prav tako uporabljajo direktno georeferenciranje, lahko uporabljamo za izdelavo oblakov točk cest ali okolice železnic. Taki oblaki točk so lahko izdelani s pomočjo laserskih skenerjev ali množice fotografij, odvisno od tega, kateri senzorji so na mobilnem snemalnem sistemu nameščeni.

Pri terestričnih postopkih lahko izmerjene podatke v prostor umestimo tudi naknadno po izmeri s pomočjo znanih oslonilnih točk in/ali razdalj na objektu snemanja (georeferenciranje ali poravnava skenogramov na slikah $3 \mathrm{c}$ in $3 \mathrm{~d}$ ). Terestrično izdelan oblak točk je lahko najprej zapisan v lokalnem koordinatnem sistemu, potem pa ga naknadno georeferenciramo, torej ga na podlagi oslonilnih točk pripnemo na nacionalni koordinatni sistem ter mu hkrati tudi spremenimo merilo.

Algoritme slikovnega ujemanja se večinoma uporablja za obdelavo velikoformatnih fotografij prostora, ki so namenjene snemanju večjih površin (slika 3b), torej topografskemu snemanju, kar je primerljivo z rezultati aerolaserskega skeniranja. Izdelava oblaka točk s slikovnim ujemanjem velikoformatnih fotografij se izvede šele potem, ko je že bila izvedena aerotriangulacija bloka aerofotografij, kjer na podlagi kalibracijskih parametrov fotoaparata najprej izračunamo parametre notranje orientacije fotografij. S pomočjo GNSS- in INS-meritev lokacije senzorja v času snemanja, oslonilnih točk (dobro vidne točke

Slika 3: Postopki izdelave oblakov točk z različnimi metodami: a) aerolasersko skeniranje, b) aerofotografiranje, c) terestrično lasersko skeniranje in d) fotografiranje objektov iz roke ali z letalnikom. 
(2)

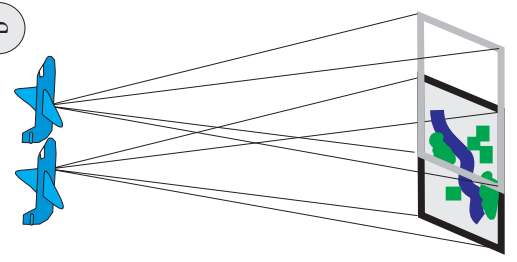

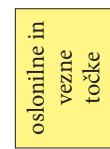
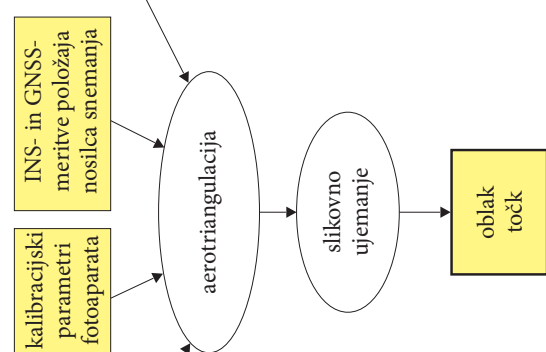

1ㄴ.

量

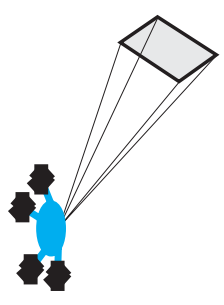

$(7$

善尊

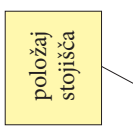

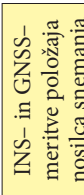

旁营
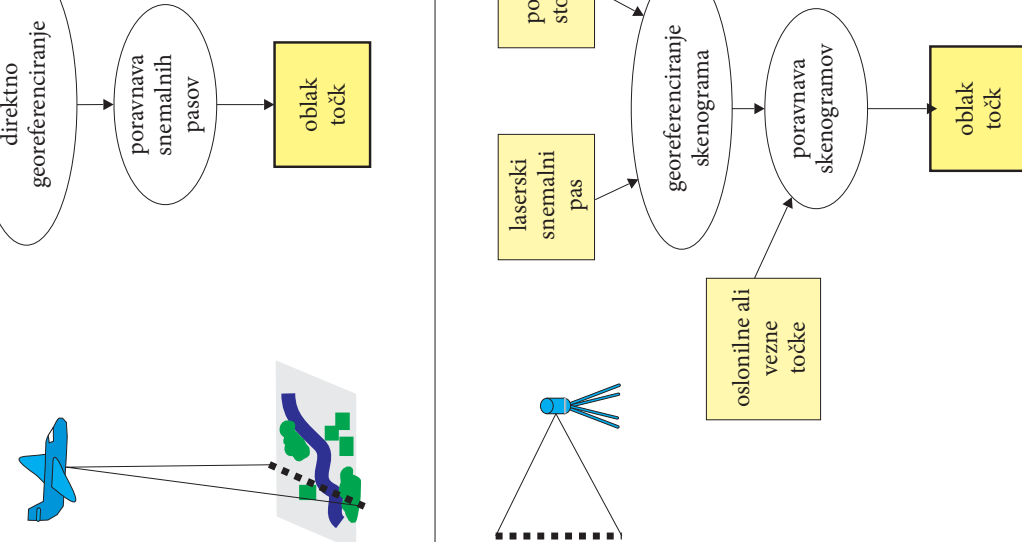

莺节 
na posnetkih s terensko izmerjenimi koordinatami v državnem koordinatnem sistemu) ter veznih točk (identične točke vidne na dveh ali več posnetkih z izmerjenimi slikovnimi koordinatami prav tako izračunane s pomočjo slikovnega ujemanja) pa izračunamo še parametre zunanje orientacije fotografij, ki podaja tri koordinate in rotacije posamezne fotografije $\mathrm{v}$ času snemanja $\mathrm{v}$ državnem koordinatnem sistemu. V tem primeru sledimo klasičnemu fotogrametričnemu postopku obdelave, pri čemer dobimo tudi ocene točnosti vmesnih faz obdelave (Remondino in sodelavci 2014). Zato lahko podamo tudi točnost končnega oblaka točk ali posredujemo v vmesnih fazah obdelave, če ne dobimo zadovoljivih rezultatov. Ta metoda se je uveljavlja za aerofotografiranje večjih mest, ker omogoča hitrejšo izdelavo

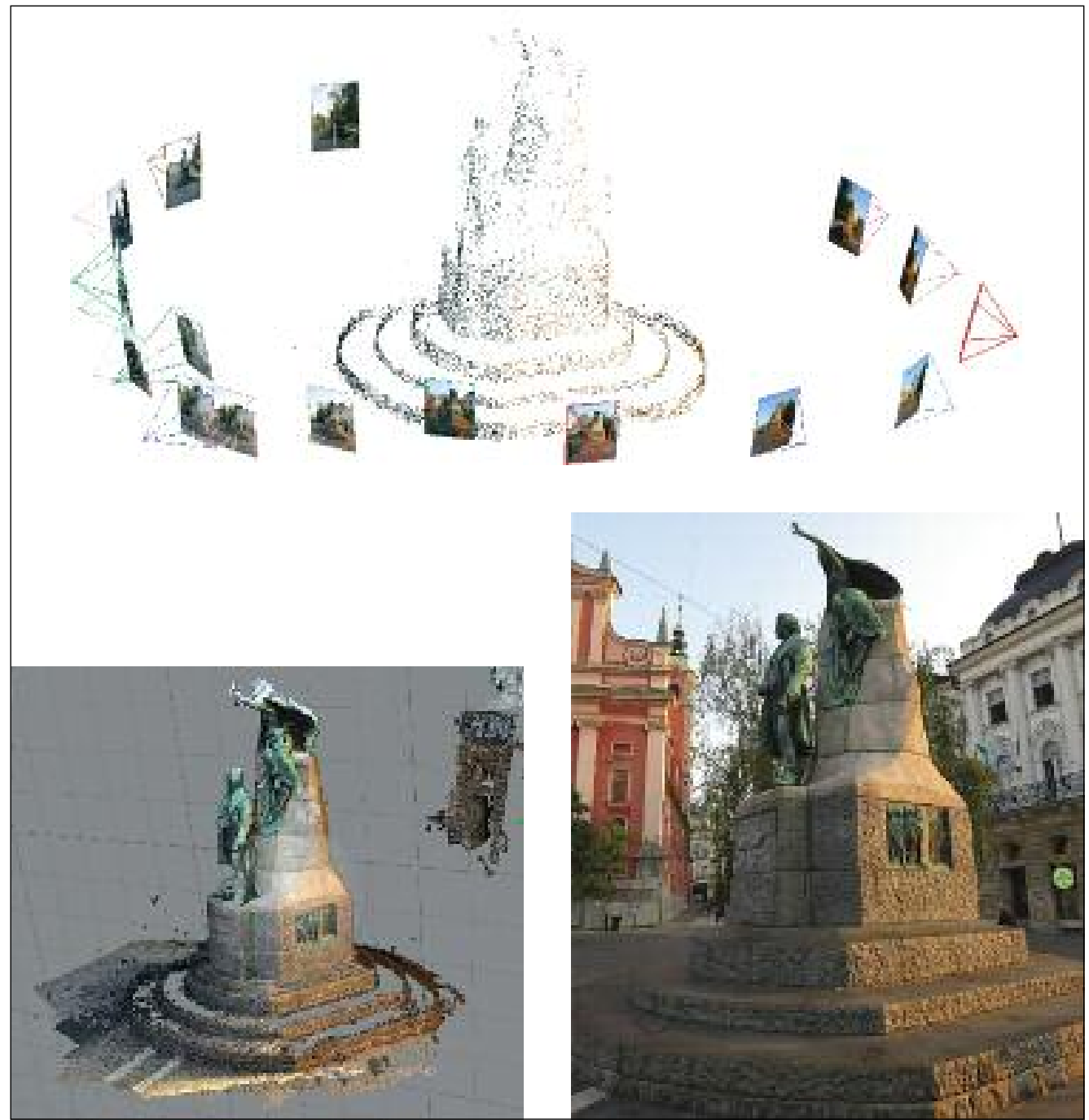

Slika 4: Oblak točk, izdelan s fotogrametrično obdelavo večjega števila bližnjeslikovnih posnetkov s programoma VisualSFM (zgoraj) in Agisoft Photoscan (spodaj levo). Na zgornji sliki so prikazana tudi stojišča fotoaparata $v$ času snemanja. Posnetek (spodaj desno) prikazuje Prešernov spomenik iz podobnega pogleda, kot je prikazan v obeh oblakih točk. 
oblaka točk z veliko višjo gostoto točk, kot aerolasersko skeniranje za enako veliko območje snemanja. Kajti aerofotografiramo lahko iz veliko višjih višin kot skeniramo $\mathrm{z}$ laserjem in zato lahko s prvo metodo hitreje posnamemo enako velika območja. Da dobimo zelo gost oblak točk in čim manj belih lis brez podatkov, so aeroposnetki narejeni z zelo velikim preklopom (vzdolžni preklop $80 \%$ ) ali celo z aerofotoparati na katerih so združeni senzorji za klasično aerofotografiranje (fotoaparat usmerjen v nadir) in fotografiranje stranskega pogleda (oblique).

V Berlinu, ki se razteza na $890 \mathrm{~km}^{2}$, so leta 2009 izvedli aerolasersko skeniranje z gostoto $5-10$ točk $/ \mathrm{m}^{2}$, leta 2013 pa aerofotografiranje $\mathrm{z}$ velikostjo slikovnega elementa na tleh $10 \mathrm{~cm}$ (ground sampling distance), ki je omogočilo izdelavo oblaka točk z gostoto 100 točk $/ \mathrm{m}^{2}$. Tako so pridobili časovno vrsto dveh oblakov točk, ki je idealna za preučevanje sprememb v prostoru (Richter 2015). Tako goste fotogrametrične oblake točk iz aerofotografij velikega formata so izdelali še za Dortmund v Nemčiji in Perth v Avstraliji (Wenzel 2015).

Algoritmi za sočasno določitev notranjih in zunanjih parametrov orientacije in hkratni izračun oblaka točk (slika 3d) se največkrat uporabljajo za pridobivanje oblakov točk manjših območij oziroma za tako imenovano bližnjeslikovno fotogrametrijo, torej za snemanje posameznih kipov (slika 2), stavb, ulic, kamnolomov in drugi manjših objektov (na primer Westoby in sodelavci 2012) (slika 4). Za takšno fotografiranje je idealna uporaba brezpilotnih letalnikov. Rezultati so direktno primerljivi z rezultati terestričnega laserskega skeniranja. Vendar s terestričnim laserskim skeniranjem dobimo oblak točk z globinsko predstavo rastja, s fotogrametričnim postopkom pa zgolj zunanji vidni sloj rastja. Pri terestričnem laserskem skeniranju je točnost izmerjene točke najbolj odvisna od razdalje do skenerja; bližnje točke imajo večjo točnost kot bolj oddaljene točke. Običajno se terestrično skenira objekte, ki niso preveč globinsko razporejeni, zato lahko točnost skenograma obravnavamo kot enovito za posamezen skenogram, ki je narejen iz enega stojišča.

Pri algoritmih za sočasno določitev parametrov orientacije in izračun oblaka točk lahko ob premajhnem številu fotografij, ki prikazujejo določeno podrobnost, pride tudi do geometrijskih deformacij v oblaku točk, za katere ne vemo, kje se nahajajo. Tako izdelan oblak točk nima več enovite točnosti. Tu so točke izračunane iz presekov žarkov. V kolikor je za izračun točk uporabljeno manjše število

\section{Preglednica 1: Prednosti (+) in (-) slabosti izdelave oblakov točk $z$ različnimi metodami.}

\section{lasersko skeniranje}

dobimo odboje na vrhu, v rastju

in pod rastjem na tleh

enovita položajna in višinska

točnost oblaka točk

\section{fotogrametrični postopki izdelave}

$+\quad$ dobimo samo odboje na vrhu rastja, pod rastjem pa ne

$+\quad$ točnost je odvisna od števila posnetkov, na katerih se točka vidi: na manj posnetkih kot se vidi, slabša je točnost take točke

enakomerna gostota neodvisna od teksture (izjema je le voda, s katere ne dobimo odbojev) sorazmerno majhna gostota točk za aerolasersko skeniranje enako velikega območja in $\mathrm{v}$ istem času opravljenega snemanja težja interpretacija samo na podlagi oblaka točk, pobarvanega na podlagi intenzitete bližnjeslikovni primer: draga in težka oprema (terestrični laserski skener)
+ območja z malo teksture dajo malo točk visoka gostota točk za aerofotografiranje velikega formata enako velikega območja in v istem času opravljenega snemanja

- lažja interpretacija na podlagi oblaka točk, pobarvanega s pomočjo fotografij

- bližnjeslikovni primer: lahko uporabimo $+$ kakršenkoli digitalni fotoaparat in snemamo iz roke 
posnetkov, so točke v oblaku točk izračunane s slabšo točnostjo. Čim se število posnetkov, na katerih se vidi določena točka, poveča, se veča nadštevilnost opazovanj in s tem se povečuje točnost izmere take točke (Remondino in sodelavci 2014). Nekateri programi omogočajo odstranjevanje točk, ki so bile izračunane samo iz dveh posnetkov, saj imajo te najslabšo točnost (na primer prostodostopni program VisualSFM). Za pridobitev zelo gostega oblaka točk, izračunanega s pomočjo samodejnih fotogrametričnih postopkov obdelave, potrebujemo veliko posnetkov, ki preučevani objekt prikažejo iz vseh mogočih zornih kotov. S tem se izognemo zastiranju različnih podrobnosti na objektu obdelave, saj pomanjkanje podrobnosti zaradi premajhnega števila fotografij hitro opazimo. Točnost je odvisna tudi od oddaljenosti točke od fotoaparata, saj so na istem posnetku bolj oddaljeni objekti prikazani v manjšem merilu kot bližnji objekti. Gostota končnega oblaka točk in njegova točnost je zelo odvisna tudi od uporabljenega algoritma v posameznem programu, ki tako obdelavo fotografij omogoča.

Iz preglednice 1 je razvidno, da imata obe metodi izdelave oblakov točk svoje slabosti in prednosti. Bistvena prednost bližnjeslikovne fotogrametrične metode je nedvomno cena senzorja, saj lahko uporabimo kakršenkoli fotoaparat, ki ga prožimo ročno ali ga namestimo na letalnik. Tudi profesionalnim letalnikom $\mathrm{v}$ zadnjih letih drastično padajo cene. Večina letalnikov omogoča samodejno snemanje izbranega objekta ali območja brez vmešavanja pilota, saj optimalno pot snemanja lahko vnaprej določimo in jo naprava sama odleti. Vendar moramo pred nakupom in uporabo letalnikov v naseljih preučiti zakonodajo s tega področja, ki postavlja določene omejitve (Uredba ... 2016).

\section{Uporaba oblaka točk za izdelavo digitalnih modelov višin - gostota točk}

Ko imamo izdelan oblak točk, ga lahko uporabimo samostojno za ročno ali polsamodejno vektorizacijo linij. Zaradi lažje fotointerpretacije vedno priporočamo kombiniranje oblaka točk z ortofotom istega območja oziroma uporabo oblaka točk, kjer so točke pobarvane glede na posnetke (slika 1b).

V kolikor pa želimo na podlagi posnetkov, narejenih za izdelavo oblaka točk, izdelati tudi ortofoto, moramo iz oblaka točk najprej izdelati digitalni model višin, ki ga potem uporabimo za izdelavo ortofota (Triglav Čekada 2016). Pri tem moramo paziti na upoštevanje najmanjše gostote talnih točk, ki je potrebna za izdelavo digitalnega modela višin $\mathrm{z}$ določeno ločljivostjo. Pred izdelavo digitalnih modelov višin moramo točke najprej razvrstiti (slika 5) v razrede kot so na primer tla, rastje, stavbe, da lahko uporabimo zgolj tisti razred, ki ga želimo prikazati v določenem modelu višin. V primeru laserskih oblakov točk odstranjujemo (klasificiramo v razrede, ki jih ne uporabimo) večkratne odboje v rastju in stavbe, v primeru fotogrametričnih oblakov točk pa odstranjujemo največkrat šum in rastje. Najmanjšo gostoto točk, ki jo potrebujemo za izdelavo digitalnega modela reliefa, lahko izračunamo z Nyquist-Shannovim teoremom vzorčenja (Triglav Čekada, Crosilla in Kosmatin Fras 2010). Za izdelavo digitalnega modela reliefa s stranico celice $1 \mathrm{~m}$ (velikost celice $1 \mathrm{~m} \times 1 \mathrm{~m}$ ), bi potrebovali 4 točke/m², za stranico celice $0,25 \mathrm{~m}$ pa že 64 točk $/ \mathrm{m}^{2}$. Ob enakomerni razporeditvi talnih točk pa je za izdelavo digitalnega modela reliefa s stranico celice $1 \mathrm{~m}$ dovolj že ena točka v posamezni celici, saj se pri interpolaciji digitalnega modela reliefa večinoma upošteva še točke v sosednjih celicah (Mongus, Triglav Čekada in Žalik 2013). Za izračun ene vrednosti digitalnega modela reliefa uporabimo vsaj štiri sosednje točke. V kolikor nimamo toliko točk, bo vrednost višine določene točke v digitalnem modelu reliefa predstavljala le interpolacijo višin sosednjih celic.

Ker oblaki točk večinoma nimajo enakomernih gostot, moramo gostoto točk na celotnem območju obdelave preveriti. To najlažje preverimo z izrisom karte gostote določenega klasifikacijskega razreda, ki ga bomo uporabili za izdelavo digitalnega modela višin - imenujmo jo karta filtriranega oblaka točk (Kerin 2014). Prav take karte gostote točk, ki prikazujejo tla, so bile izdelane za vse bloke laserskega skeniranja Slovenije. Predstavljene so bile v tehničnih poročilih posameznih blokov skeniranja in s tem uporabnikom omogočijo vpogled v realno število laserskih točk, ki se jih je uporabilo za izdelavo digitalnega modela reliefa $\mathrm{z}$ velikostjo celice $1 \mathrm{~m} \times 1 \mathrm{~m}(\mathrm{DMR} 1)$ na območju posameznega bloka skeniranja. 


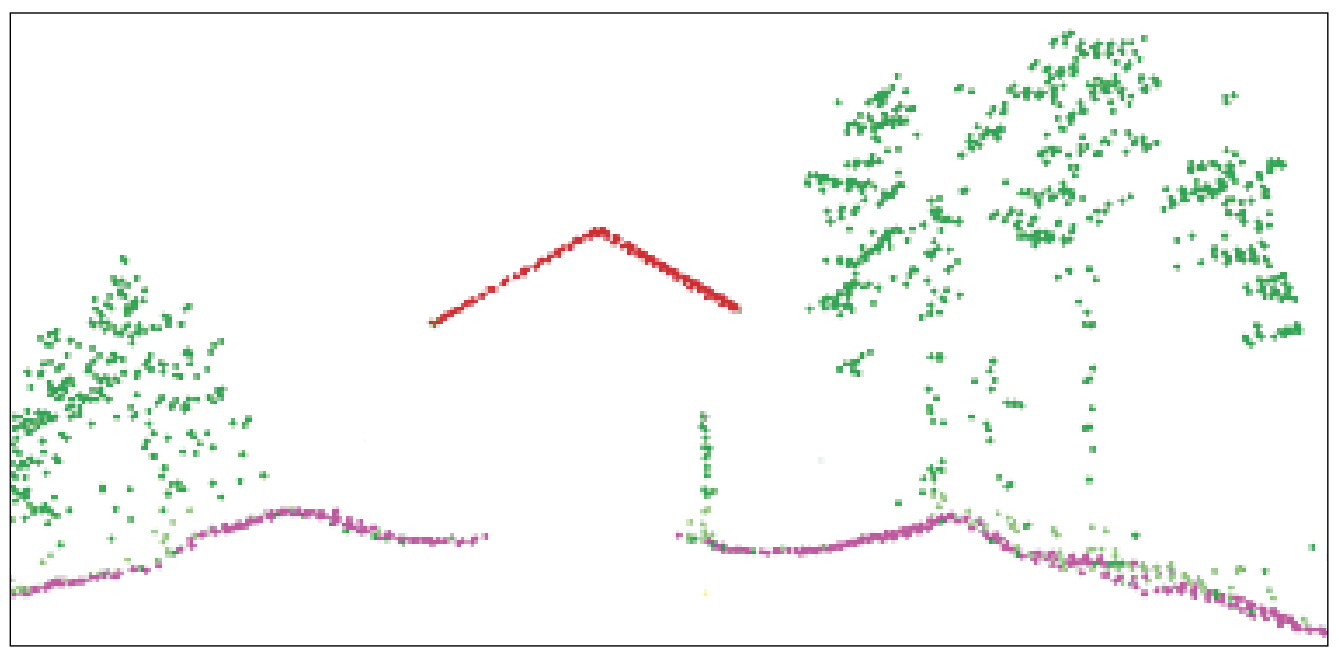

Slika 5: Stranski pogled na klasificiran oblak točk iz slike 2: temno zelena do svetlo zelene - rastje treh različnih višin, vijoličasta - tla in rdeča - stavbe.

Pod gostimi gozdovi je bila gostota točk reliefa povprečno 0,5 točk $/ \mathrm{m}^{2}$, na območjih travnikov pa 2 točki $/ \mathrm{m}^{2}$ (Triglav Čekada in Bric 2015). To pomeni, da moramo pri uporabi laserskega DMR1 v gozdu vedeti, da je le-ta ponekod preveč zglajen zaradi uporabe premajhnega števila točk v postopku interpolacije. To pa se kaže tako, da na podobi analitičnega senčenja DMR1 relief pod rastjem in na odprtem terenu nista enako gladka.

Karto gostot filtriranega oblaka točk za izdelavo digitalnega modela reliefa je smiselno priložiti tudi ortofotu, ki je bil izdelan s pomočjo tega digitalnega modela reliefa, saj bomo na ta način vedeli, kje na ortofotu lahko pričakujemo največja odstopanja. Izdelava karte gostot in/ali karte točnosti je še posebej priporočljiva za fotogrametrično izdelane oblake točk, kjer sta točnost in gostota točk zelo odvisni od števila posnetkov, na katerih se določen del objekta vidi.

Oblak točk predstavlja podatke osnovnih meritev. Digitalni model reliefa, izdelan na podlagi oblaka točk, je že interpolirana oblika izdelka, ki je obremenjen tako z napakami izdelave oblaka točk kot napakami klasifikacije točk $\mathrm{v}$ razred tla in napakami uporabljene interpolacijske metode za izdelavo digitalnega modela reliefa (Mongus, Triglav Čekada in Žalik 2013). Prav tako moramo paziti, kako velike celice digitalnega modela reliefa uporabljamo in za kakšen namen. Bližnjeslikovni fotogrametrično izdelani oblaki točk omogočajo izdelavo oblakov točk velikih gostot, kar nadalje omogoča izdelavo zelo podrobnih digitalnih modelov površja. V kolikor ne izkoristimo celotnega potenciala tako velikih gostot, torej ne uporabimo dovolj majhne celice, lahko pri izračunu prostornin hitro pridobimo napako prostornine večjo od $5 \%$, ki po Urbančiču in sodelavcih (2015) ni več sprejemljiva za izračune prostorninskih sprememb. Če na primer vzamemo stranico celice digitalnega modela reliefa $5 \mathrm{~m}$, namesto da bi uporabili stranico celice $0,5 \mathrm{~m}$, katere izdelavo bi ta gostota točk še dopuščala, dobimo za območje veliko okoli enega hektarja napako pri prostorninskih spremembah večjo od $5 \%$ merjene prostornine.

\section{Primerjava dveh oblakov točk oziroma poravnava oblakov točk}

V kolikor želimo preučevati majhne spremembe v prostoru, moramo biti pozorni tudi na točnost georeferenciranja oblaka točk, torej kje v prostoru se oblak točk nahaja glede na uporabljen koordinatni sistem. Kajti, zaradi različnih oslonilnih točk, ki so bile uporabljene v postopku izdelave oblaka 
točk, ali različnih rezultatov direktnega georeferenciranja, sta lahko dva oblaka višinsko in/ali položajno zamaknjena. Zavedati se moramo, da lahko položajne in višinske napake doda tudi koordinatni sistem, v katerem imamo podatke podane oziroma v katerega so bili podatki transformirani, zato da jih lahko uporabljamo. Največjo napako dobimo, če za transformacijo med koordinatnimi sistemi ne uporabimo optimalne transformacije, ki daje najnatančnejše rezultate po transformaciji. Vendar tudi, če uporabimo optimalno transformacijo, so podatki v različnih sistemih zapisani različno točno, ker je točnost odvisna od realizacije koordinatnega sistema. Tako je višinski sistem zelo odvisen od realizacije geoida, horizontalni pa je lahko nehomogen zaradi zgodovinskih razlogov, kot je to v primeru ravninskega koordinatnega sistema D48/GK (Gauss-Krügerjeva projekcija) (Bric, Berk in Triglav Čekada 2013).

Kot primer opišimo podatke laserskega skeniranja Slovenije, ki so bili najprej zajeti v ravninskem koordinatnem sistem D96/TM (Transverzalna Merkatorjeva projekcija) in elipsoidnih višinah, naknadno pa transformirani v D96/TM in nadmorske višine ter na koncu še v ravninski koordinatni sistem D48/GK, ki ga še vedno uporablja največ uporabnikov. Tako podatki aerolaserskega skeniranja, ki imajo v D96/TM in nadmorskih višinah opredeljeno točnost na podlagi večjega števila kontrolnih točk (položajna točnost $30 \mathrm{~cm}$, višinska $15 \mathrm{~cm}$ ), nimajo enake položajne točnosti v D48/GK, saj ravninski koordinatni sistem D48/GK ni homogen. Med lasersko izmero in podatki, zapisanimi v D48/GK, smo imeli v tem primeru opravljeni dve transformaciji, pri čemer je vsaka obremenjena s svojimi napakami. Podobno je pri uporabi podatkov, zajetih v okviru fotogrametričnega zajema na podlagi stereoposnetkov Cikličnega aerofotografiranja Slovenije (CAS). Od leta 2009 naprej se v projektu CAS uporablja nov ravninski koordinatni sistem D96/TM, v katerem so tudi podani vsi rezultati projekta. Stereozajem se torej lahko izvaja zgolj v D96/TM, v katerem imamo zapisane orientacijske parametre posnetkov. V kolikor želimo izmero primerjati s stereozajemom iz na primer CAS 2006, ki je bil izveden v D48/GK, moramo enega izmed rezultatov transformirati (glej Triglav Čekada in Zorn 2014). $S$ transformacijo med koordinatnima sistema enemu od rezultatov "pokvarimo« položajno točnost za največ en decimeter (Berk, Komadina in Triglav 2011).

Dandanes ob uradni veljavnosti dveh ravninskih koordinatnih sistemov (D48/GK in D96/TM) in ob skorajšnji novi realizaciji geoida ter s tem spremembi v višinskem koordinatnem sistemu (sprememba višinskega datuma), smo primorani preverjati tudi položajno in višinsko skladnost dveh nizov podatkov ali oblakov točk ob izvajanju različnih analiz sprememb v prostoru. Najprej moramo preveriti višinsko in položajno skladnost na območju brez sprememb, potem pa izvedemo še višinsko in/ali položajno poravnavo dveh oblakov točk.

Položajno skladnost dveh oblakov točk lahko preverimo na dva načina. Prvi, ki je tudi največkrat uporabljen, je preverba obeh oblakov točk na istih kontrolnih točkah, ki so bile neodvisno izmerjene z bolj natančno metodo izmere, na primer z GNSS-metodo izmere. Na ta način lahko določimo absolutna odstopanja posameznega oblaka točk od referenčnih kontrolnih točk. Če takšnih kontrolnih točk nimamo, lahko izvedemo le relativno primerjavo med dvema oblakoma točk, kjer pa ne dobimo odstopanj od referenčnih vrednosti, torej ne moremo povedati, kateri oblak točk je bolj točno georeferenciran, lahko zgolj pridobimo razliko med tema dvema oblakoma točk. Vendar so tudi relativne vrednosti dovolj, da en oblak točk poravnamo na drugega (co-registration). Tudi le relativna poravnava dveh oblakov točk nam omogoča bolj točno izmero višinskih ali prostorninskih odstopanj na območju sprememb, kot če poravnave oblakov točk predhodno ne bi izvedli (Chen in sodelavci 2014).

Poravnavo dveh oblakov točk izvedemo s pomočjo kontrolnih točk ali s poravnavo ploskev oblakov točk (Gruen in Akca 2005). Prva metoda zahteva več terenskega dela, torej izmere kontrolnih točk $\mathrm{z}$ natančno geodetsko metodo izmere, ki je časovno potratna. Na kontrolnih točkah izmerimo pomike po višini in po položaju ter največkrat oblak točk samo premaknemo za povprečno vrednost odstopanj, pridobljeno iz uporabljenih kontrolnih točk, torej oblakov med sabo ne vrtimo. Druga metoda pa se dodatnemu terenskemu delu izogne, saj primerjamo med sabo le dva oblaka točk, s tem da zanju izračunamo digitalna modela višin, bodisi reliefa ali površja, odvisno od tega, kakšne oblake primerjamo. Rezultat 

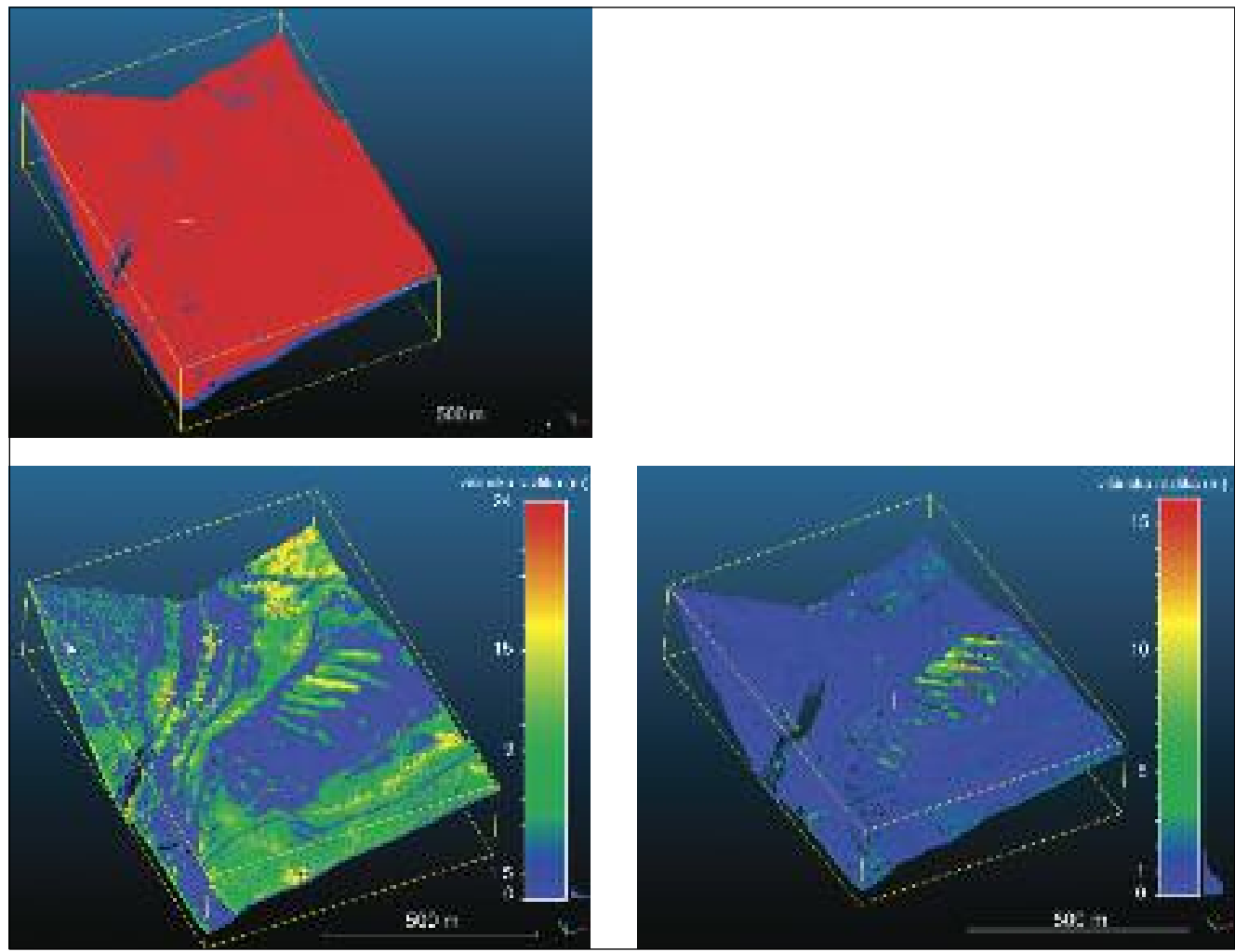

Slika 6: Odstopanja med dvema laserskima oblakoma točk v kamnolomu v Solkanu leta 2009 in leta 2015, izrisana v programu CloudCompare. Zgoraj: primerjava dveh oblakov točk pred poravnavo; spodaj levo: primerjava oblaka točk $z$ rastjem in oblaka brez rastja po poravnavi - vidimo še vse razlike $v$ višini rastja; spodaj desno: primerjava dveh oblakov točk brez rastja po poravnavi - ostanejo le prave višinske razlike.

so transformacijski parametri, ki podajajo pomike in rotacije med dvema oblakoma točk, da se transformirani oblak točk najbolje prilega netransformiranemu. Iščemo transformacijske parametre 7-parametrične podobnostne transformacije (tri rotacije, trije pomiki in ena sprememba merila) s pomočjo pogoja, da se ploskvi, ki opisujeta oblaka točk, najmanj razlikujeta med seboj tako po višini kot po položaju. Rešitev dobimo z uporabo izravnave po metodi najmanjših kvadratov (least square matching) (Gruen in Akca 2005). V enostavnejših izvedbah pa iščemo samo višinske pomike med dvema oblakoma točk oziroma ploskvama (na primer Gläser in sodelavci 2013).

Računalniški programi, ki omogočajo izdelavo oblaka točk, večinoma omogočajo tudi poravnavo oblakov točk na podlagi kontrolnih točk (na primer 3Dsurvey). Za poravnavo oblakov točk brez kontrolnih točk pa moramo uporabiti posebne programe (na primer CloudCompare). Poravnavo oblakov točk izvajamo samo na območju brez sprememb, torej moramo pri preučevanju prostorninskih sprememb uporabiti dovolj veliko okolico preučevanega objekta, da bomo lahko izvedli poravnavo oblakov točk z zadovoljivo točnostjo. Prav tako moramo paziti, da poravnavamo samo klasifikacijski razred, ki opisuje tla oziroma objekte blizu tal, da ne primerjamo napačnih vsebin. Tako smo za izdelavo slike 6 izvozili samo nekaj klasifikacijskih razredov iz laserskih oblakov točk za leti 2009 in 2015. Na zgornji sliki 6 sta prikazana oblaka točk pred poravnavo (višinska razlika med oblakoma točk je pretirana zaradi preglednejšega prikaza). Na spodnjih slikah 6 sta oblaka že poravnana. Na sliki 6 (spodaj levo) vidimo, 
da smo poravnavali med sabo napačne podatke, saj je en oblak točk vseboval klasifikacijo tla in stavbe, drug pa tla, stavbe in visoko rastje. Zato na tej sliki, ki predstavlja višinske razlike med oblakoma točk, vidimo še vso visoko rastje kot višinsko razliko oblakov točk; na območju gozdov je ta do $25 \mathrm{~m}$. Na sliki $6 \mathrm{c}$ smo visoko rastje iz oblaka odstranili. Zato v kamnolomu Solkan ostanejo vidne prave višinske spremembe, visoke do $15 \mathrm{~m}$, ter nekatere manjše spremembe na območjih s spremenjenimi stavbami oziroma drugačno klasifikacijo stavb. Klasifikacija stavb v obeh oblakih ni bila narejena $\mathrm{z}$ enako programsko opremo in se zato razlikuje.

\section{Sklep}

Predstavljene so štiri metode, s pomočjo katerih lahko izdelamo oblak točk: aerolasersko skeniranje, aerofotografiranje velikega formata, fotografiranje iz tal ali letalnika ter terestrično lasersko skeniranje. Vsaka metoda ima svoje prednosti in slabosti, katerih se moramo ob uporabi oblakov točk zavedati in jih ob izdelku tudi zapisati v obliki različnih mer kakovosti (na primer višinska, položajna točnost, gostota točk na enoto površine, popolnost oblaka točk - ali so vsa mesta pokrita z enako gostoto točk).

Ob izvajanju časovnih analiz sprememb v prostoru, lahko uporabljamo oblake točk, izdelane z različnimi metodami izmere. Za dosego najboljšega rezultata, torej za najbolj natančen izračun višinskih ali prostorninskih sprememb, moramo pred uporabo oblaka točk med sabo primerjati. Najpomembneje je, da preučimo gostoto točk ter položajno in višinsko poravnavo oblakov točk. V kolikor imamo na območju obravnave vsaj nekaj obstoječih kontrolnih točk uporabimo za poravnavo te. Če pa ne, potem za poravnavo oblaka točk ali njihove izdelke (digitalni model reliefa) uporabimo različne programe. Ob vse širši prosti dostopnosti različnih zelo podrobnih oblakov točk (na primer lasersko skeniranje Slovenije), oziroma možni ponovni uporabi že obstoječih podatkov iz javnih ustanov ter vse bolj razširjeni uporabi novega ravninskega koordinatnega sistema D96/TM, se moramo zavedati, da je preverba poravnave dveh oblakov točk nujna pred njuno uporabo za izračun višinskih ali prostorninskih sprememb.

Zahvala: Delo je bilo financirano v okviru temeljnega raziskovalnega projekta J2-5479 Javne agencije za raziskovalno dejavnost Republike Slovenije.

\section{Viri in literatura}

3Dsurvey. Medmrežje: http://www.3dsurvey.si/ (23.9.2016).

Agisoft Photoscan. Medmrežje: http://www.agisoft.com/ (23.9.2016).

Berk, S., Komadina, Ž., Triglav, J. 2011: Analiza skladnosti D48/GK- in D96/TM-koordinat zemljiškokatastrskih točk v Pomurju. Geodetski vestnik 55-2. DOI: https://doi.org/10.15292/ geodetski-vestnik.2011.02.269-283

Bric, V., Berk, S., Triglav Čekada, M. 2013: Zagotavljane kakovosti georeferencioranja podatkov aerolaserskega skeniranja za upravljanje voda. Geodetski vestnik 57-2. DOI: https://doi.org/10.15292/ geodetski-vestnik.2013.02.271-285

Chen, Z., Zhang, B., Han, Y., Zuo, Z., Zhang, X. 2014: Modeling accumulated volume of landslides using remote sensing and DTM data. Remote Sensing 6-2. DOI: https://doi.org/10.3390/rs6021514

CloudCompare. Medmrežje: http://www.danielgm.net/cc/ (23.9. 2016).

Gläser, P., Haase, I., Oberst, J., Neumann, G. A. 2013: Co-registration of laser altimeter tracks with digital terrain models and applications in planetary science. Planetary and Space Science 89. DOI: https://doi.org/10.1016/j.pss.2013.09.012 
Gruen, A. 2012: Development and status of image matching in photogrammetry. The Photogrammetric Record 27-137. DOI: https://doi.org/10.1111/j.1477-9730.2011.00671.x

Gruen, A., Akca, D. 2005: Least squares 3D surface and curve matching. ISPRS Journal of Photogrammetry and Remote Sensing 59-3. DOI: https://doi.org/10.1016/j.isprsjprs.2005.02.006

Kerin, A. 2014: Uporaba posnetkov z brezpilotnega zračnega plovila za izdelavo digitalnega modela reliefa. Diplomsko delo, Fakulteta za gradbeništvo in geodezijo Univerze v Ljubljani. Ljubljana.

Kosmatin Fras, M., Valič, R., Bone, M., Mesarič, M. 2015: Uporaba malih brezpilotnih letalnikov za zajem prostorskih podatkov. Geodetska (r)evolucija: zbornik posveta 43. geodetskega dne. Ljubljana.

Leberl, F., Irschara, A., Pock, T., Meixner, P., Gruber, M., Scholz, S., Wiechert, A. 2010: Point clouds: Lidar versus 3D vision. Photogrammetric Engineering and Remote Sensing 76-10. DOI: https://doi.org/10.14358/PERS.76.10.1123

Mongus, D., Triglav Čekada, M., Žalik, B. 2013: Analiza samodejne metode za generiranje digitalnih modelov reliefa iz podatkov lidar na območju Slovenije. Geodetski vestnik 57-2. DOI: https://doi.org/10.15292/geodetski-vestnik.2013.02.045-259

Remondino, F., Spera, M. G., Nocerino, E., Menna, F., Nex, F. 2014: State of the art in high density image matching. The Photogrammetric Record 29-146. DOI: https://doi.org/10.1111/phor.12063

Richter, R. 2015: 4D point clouds - challenges, solutions and applications. CapturingReality. Medmrežje: http://www.capturingrealityforum.com/wp-content/uploads/CRF15_ConferenceProgramme.pdf (23. 9. 2016).

Triglav Čekada, M. 2016: Navidezna zvrnjenost objektov na državnem ortofotu ali kaj moramo vedeti, ko uporabljamo državni ortofoto. Geografski vestnik 88-1. DOI: https://doi.org/10.3986/GV88107

Triglav Čekada, M., Bric, V. 2015: Končan je projekt laserskega skeniranja Slovenije. Geodetski vestnik 59-3.

Triglav Čekada, M., Crosilla, F., Kosmatin Fras, M. 2009: A simplified analytical model for a-priori lidar point-positioning error estimation and a review of lidar error sources. Photogrammetric Engineering and Remote Sensing 75-12. DOI: https://doi.org/10.14358/PERS.75.12.1425

Triglav Čekada, M., Crosilla, F., Kosmatin Fras, M. 2010: Teoretična gostota lidarskih točk za topografsko kartiranje v največjih merilih. Geodetski vestnik 54-3. DOI: https://doi.org/10.15292/ geodetski-vestnik.2010.03.403-416

Triglav Čekada, M., Zorn, M. 2014: Ugotavljanje intenzivnosti geomorfnih procesov s pomočjo posnetkov Cikličnega aerofotografiranja Slovenije. Geografski vestnik 86-2. DOI: https://doi.org/10.3986/ GV86206

Urbančič, T., Grahor, V., Koler, B. 2015: Vpliv velikosti celice in metod interpolacij na izračunano prostornino. Geodetski vestnik 59-2. DOI: https://doi.org/10.15292/geodetski-vestnik.2015.02.231-245

Uredba o sistemu brezpilotnih zrakoplovov. Uradni list Republike Slovenije 52/2016. Ljubljana.

VisulaSFM. Medmrežje: http://ccwu.me/vsfm/ (23.9. 2016).

Wenzel, K. 2015: Large scale photogrammetric 3D city capturing. CapturingReality. Medmrežje: http://www.capturingrealityforum.com/wp-content/uploads/CRF15_ConferenceProgramme.pdf (23.9.2016).

Westoby, M. J., Brasington, J., Glasser, N. F., Hambrey, M. J., Reynolds, J. M. 2012: »Structure-from Motion' photogrammetry: A low-cost, effective tool for geoscience applications. Geomorphology 179. DOI: https://doi.org/10.1016/j.geomorph.2012.08.021

\section{Summary: Photogrammetric and lidar point clouds}

(translated by the author)

Point cloud is a data format where an object of interest is described in the form of very dense points, which are not interconnected and where each point has its own coordinates and attributes. Point clouds 
have emerged with the introduction of the laser scanning (lidar) in surveying. However, the point clouds are not limited just to the laser scanning, since they can be produced by other methods, too. Following the increasing spread of drones (unmanned aerial vehicles), the photogrammetric methods for point cloud production are gaining strength. The drones are mainly equipped with photographic cameras and not laser scanners, due to greater affordability of the former. Photogrammetric point clouds can also be produced from photographs made by hand with various non-metric cameras and smart phones. Thus, we can divide the point cloud production in laser and photogrammetric processes (Figure 3 ).

In the last decade the international photogrammetric community has accepted point clouds as separate end products; in the past they had been recognised only as an optional intermediate step in the production of geometrically correct digital elevation models.

Both aerial and terrestrial laser scanning give directly measured point clouds. Their essential feature is that one laser pulse on its way through the vegetation is reflected from several points (on different branches, leaves) and therefore we get more than one return from each pulse (Figure 2). Therefore, on vegetated areas greater overall point densities are achieved than on built up areas and areas without vegetation, where each pulse is reflected only from one point. Such point clouds enable studies of the vertical forest structure and other diverse vegetation studies (e.g. forest density, distribution of tree species).

Photogrammetric point clouds are calculated by automatic processing of a large number of photographs showing the object of interest from a wide array of different angles. However, since the point cloud is obtained from photographs, which show only the top layer of the vegetation, a single point on the top of vegetation is calculated and no points under the vegetation can be extracted (Figure 2).

Automatic processing of a large number of photographs is mainly described as the use of photogrammetric algorithms for very dense image matching (Figure 3c) or computer vision algorithms for the simultaneous determination of internal and external parameters of orientation and simultaneous calculation of 3D point clouds e.g. Structure from Motion (SfM) (Figure 3d) (Remondino et al. 2014). In this paper we call all such products photogrammetric point clouds to emphasise that they were derived from photographs. Photogrammetric point clouds are becoming denser and in some cases even surpass the products of laser scanning in density (Leberl et al. 2010; Gruen 2012). This has become possible only due to the introduction of new algorithms and hardware improvements, which enable programing on the graphical card to enable a much faster calculation (Remondino et al. 2014).

Using different interpolation methods we can produce different digital elevation models from point clouds: from different surface models to terrain model. They enable the analysis of diverse volume changes from active landslides to the growth of vegetation. Photographs and point clouds can be used for the production of orthophotos. Additionally, from the point clouds the topologically ordered wireframes for 3D printing can be made. Finally, they can be used for cartographic map production.

However, when using two point clouds to calculate the volume or elevation change, we need to examine, if the density of points in the area of interest in both point clouds is satisfactory and whether they are correctly geo-referenced. We suggest to map filtered point cloud densities for the whole area of interest.

Correctness of geo-referencing can be checked using the field control points or with co-registration of two point clouds. If we use control points we can measure the positional and vertical difference between the control points and each point cloud, then we move the point cloud for the measured difference to better fit the reference control points. Using control points we can also see which point cloud was better geo-referenced in the first place, therefore we measure absolute differences between the control points and the point cloud. If we use co-registration without control points, we compare relative differences between two filtered point clouds or better between two digital terrain models. We cannot say which point cloud was geo-referenced better in the first place. We calculate the relative difference between two point clouds and move one point cloud for this difference to better match to the other (Figure 6). 
When general public has free access to a variety of high resolution point clouds (e.g. Laser scanning of Slovenia) in two different Slovenian official coordinate systems (D48/GK and D96/TM) they must be aware that the verification of point cloud co-registration represents an essential preliminary procedure before using such point clouds for volume or height change studies. If using unverified coregistration the calculated height and volume differences cannot be trusted. 